\title{
Compensatory strategies for the alveolar flap [r] production in the presence of ankyloglossia
}

\begin{abstract}
Roberta Lopes de Castro Martinelli ${ }^{1}$ https://orcid.org/0000-0002-5791-2575

Irene Queiroz Marchesan² https://orcid.org/0000-0001-6483-7457
\end{abstract}

Giédre Berretin-Felix ${ }^{3}$ https://orcid.org/0000-0002-8614-2805
Hospital Santa Therezinha, Brotas, São Paulo.

CEFAC Saúde e Educação, São Paulo, São Paulo.

Universidade de São Paulo - USP, Faculdade de Odontologia de Bauru, Bauru, São Paulo, Brasil.

Conflict of interests: Nonexistent

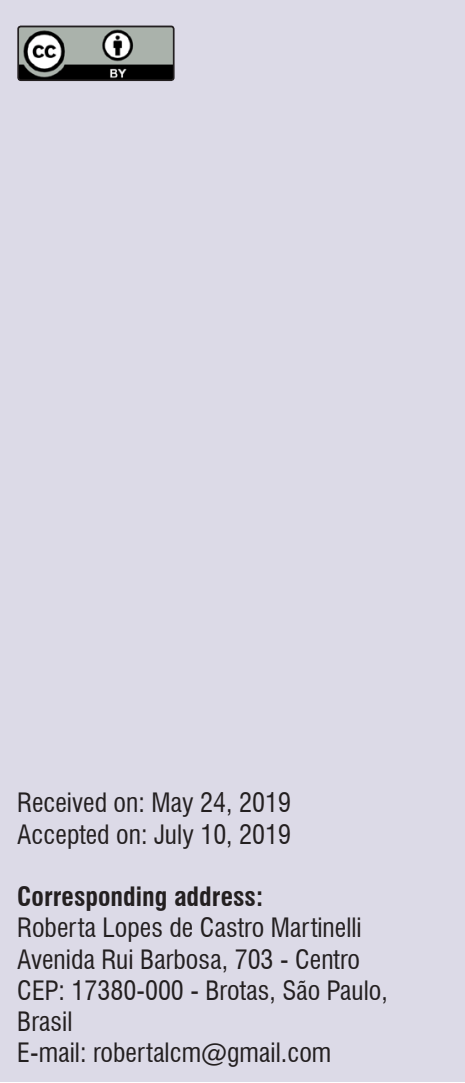

\section{ABSTRACT}

Purpose: to analyze the compensatory strategies used by subjects with ankyloglossia for the production of the consonantal alveolar flap sound /r/.

Methods: a cross-sectional analytic observational comparative study was conducted with 88 subjects, 44 being diagnosed with ankyloglossia and 44 with normal lingual frenulum, matched by age and gender. They were asked to repeat the syllable /ra/ five times in a row. Video recordings of the speech were taken. Frame by frame analysis of all recordings were performed to verify tongue, lip, and mandible movements during the production of the alveolar flap. The analysis of the films was performed by two Speech Language Pathologists specialized in Orofacial Myofunctional Disorder. Fisher's Exact Test was used for statistical treatment $(p \leq 0.05$.)

Results: the frame by frame analysis of the alveolar flap production of subjects with and without ankyloglossia showed that subjects with ankyloglossia performed several compensatory strategies when producing this sound. There was a statistically significant difference $(p=0.001)$ when subjects with and without ankyloglossia were compared.

Conclusion: subjects with ankyloglossia used several lip, tongue, and mandible compensatory strategies to produce the Brazilian Portuguese consonantal alveolar flap /r/.

Keywords: Lingual Frenum; Ankyloglossia; Speech; Articulation Disorders 


\section{INTRODUCTION}

The presence of a frenulum in the human body occurs when there was, originally, an embryonic fusion of two surfaces, which later are separated during normal growth. The tongue and the floor of the mouth are originally fused and then separated during the embryonic development, originating the lingual frenulum ${ }^{1,2}$ Thus ankyloglossia results from the incompletion of this process $^{2}$. Ankyloglossia can be an isolated alteration ${ }^{3}$ or it can be related to genetic syndromes ${ }^{4-6}$.

The point of frenulum attachment to the tongue and to the floor of the mouth does not change over time $^{7}$; moreover, its histological constitution does not allow spontaneous rupture or elongation by means of exercises $^{8}$. Those facts justify the importance of early diagnosis for ankyloglossia.

A recent study has shown that the lingual frenulum is a dynamic three-dimensional structure formed by a central fold in a layer of fascia that extends across the floor of mouth and varies in morphology on a spectrum ${ }^{9}$. With the anterior tongue in a resting position and the tongue's ventral surface in contact with the anterior floor of mouth mucosa, the contour of the floor of mouth fascia is horizontal and it is not under tension. With all anterior tongue movements, the central attachment of the fascia to the ventral tongue surface creates passive movement of the floor of mouth fascia, together with the overlying oral mucosa ${ }^{9}$. Anterior and mid tongue elevation and/or retraction create tension in the fascial layer, drawing the fascia and the overlying mucosa up into a midline sagittal fold that forms the lingual frenulum ${ }^{9}$. This diaphragm-like structure suspends the tongue and the floor of mouth structures to stabilize tongue position while allowing freedom of movement. With tongue elevation, the prominence and visual appearance of the lingual frenulum fold vary significantly between individuals.

In some subjects, the anatomical variation in frenulum morphology may create tongue movement restriction, such that there is an imbalance between these roles of stability and mobility ${ }^{9}$. Research on task specific tongue biomechanics help us to understand how movement restriction caused by the lingual frenulum may impact variable on different tongue activities such as the speech ${ }^{10-13}$.

For an adequate speech production, the anatomo-functional structures of the stomatognathic system must be balanced in order to perform the required movements ${ }^{14}$. Initial children's speech acquisition contains generally obstructive and nasal sounds followed by the fricative and liquid sounds. The lateral and non-lateral liquid sounds are the last sounds to be acquired due to their complexity. The liquid sounds of the Brazilian Portuguese are /I/, / $/$ / and / $/$. In cases of speech alteration those are the most altered sounds ${ }^{15}$.

The fast-synchronous and precise tongue movements are essential for an adequate articulation, mainly for the consonantal alveolar flap $/ \mathrm{r}^{/ 16,17}$ being that the mobility of the apex of the tongue interferes directly with the sound production.

Unusual movements of the lips, tongue and mandible performed by subjects with ankyloglossia during speech production are directly or indirectly related to the restriction of the vertical movements of the tongue; however, they do not interfere with speech intelligibility ${ }^{18,19}$ Although some authors correlate ankyloglossia with speech production alterations ${ }^{20-22}$, the alveolar flap production by subjects with ankyloglossia is still poorly described in the literature. This study aimed to analyze the compensatory strategies used by subjects with ankyloglossia for the production of the consonantal alveolar flap sound $/ r /$.

\section{METHODS}

A cross-sectional analytic observational comparative study was conducted with 88 subjects who had been assessed in a health care institution from 2016 to 2018. The research project was approved by the Research Ethics Committee of CEFAC, under number 1.181.172. All participants signed the Informed Consent Form and Free and Clarified Assent Form (for children), according to Resolution CNS 466/12-National Health Council.

The study included 44 subjects diagnosed with ankyloglossia, (experimental group - EG) by means of a specific protocol23 and 44 subjects without ankyloglossia (control group- CG) aged between 7 and 42 years. The 44 subjects without ankyloglossia were matched for age and gender. Of the 44 subjects diagnosed with ankyloglossia 17 were female and 27 male, average age 13.6 years old.

The exclusion criteria for both groups were: presence of phonological deviations, hearing impairment history, temporomandibular joint disorder, mental deficiency, neurological disorder, genetic syndromes, mouth breathing, cleft palate, and subjects who underwent surgery to release lingual frenulum or speech therapy.

Both groups were individually assessed in the same room by the first author of this study. Speech samples from all subjects were taken during the production of a sequence of syllables using a Canon 
PowerShot SX530HS camera. The camera was placed at a distance of 15 centimeters having the lower third of the face focused. Each subject was asked to repeat the syllable /ra/ five times in a row. All recordings were converted into slow motion for later frame by frame analysis of tongue, lip, and mandible movements during the production of the alveolar flap. The analysis of the films was performed by two Speech Language Pathologists specialists in Orofacial Myofunctional Disorder, experienced in lingual frenulum assessment. All tongue, lip and jaw movements visually observed frame by frame by the two specialists were recorded in spreadsheets for further statistical treatment.

Statistical analysis was performed using the SPSS (Statistical Package for the Social Sciences), version 24.0. Fisher's Exact Test was used to verify possible differences in the alveolar flap production in subjects with and without ankyloglossia at a $5 \%$ significance level $(p \leq 0.05)$.

\section{RESULTS}

The frame by frame analysis of the alveolar flap production of subjects with and without ankyloglossia demonstrated that subjects with ankyloglossia performed several compensatory strategies when producing this sound, as shown in Table 1.

There was a statistically significant difference $(p=0.001)$ when both the subjects with and without ankyloglossia were compared. The subjects with ankyloglossia had reduced mouth opening, mandible deviation, elevation of the lateral sides of the tongue, tongue deviation, cupping of the tongue, mandibular vertical movements, tongue blade deformation, and variation of the articulation point when producing the alveolar flap (Figure 1). Those strategies were not observed in the subjects without ankyloglossia. Of the 44 subjects with ankyloglossia only three subjects had lip motions when producing the alveolar flap and only two had variations of the manner of articulation. Those strategies were not observed in the subjects without ankyloglossia.

Table 1. Compensatory strategies performed by subjects with and without ankyloglossia to produce the alveolar flap sound

\begin{tabular}{|c|c|c|c|c|c|c|}
\hline \multirow{3}{*}{ Variable } & \multirow{3}{*}{ Category } & \multicolumn{4}{|c|}{ Ankyloglossia } & \multirow{3}{*}{$\mathrm{p}$-Value } \\
\hline & & \multicolumn{2}{|c|}{ No } & \multicolumn{2}{|c|}{ Yes } & \\
\hline & & Frequency & $\%$ & Frequency & $\%$ & \\
\hline \multirow{2}{*}{ reduced mouth opening } & no & 43 & $97.70 \%$ & 6 & $13.60 \%$ & \multirow{2}{*}{$<0.001^{*}$} \\
\hline & yes & 1 & $2.30 \%$ & 38 & $86.40 \%$ & \\
\hline \multirow{2}{*}{ mandible deviation } & no & 44 & $100.00 \%$ & 22 & $50.00 \%$ & \multirow{2}{*}{$<0.001^{*}$} \\
\hline & yes & 0 & $0.00 \%$ & 22 & $50.00 \%$ & \\
\hline \multirow{2}{*}{$\begin{array}{l}\text { elevation of the lateral sides of the } \\
\text { tongue }\end{array}$} & no & 44 & $100.00 \%$ & 17 & $38.60 \%$ & \multirow{2}{*}{$<0.001^{*}$} \\
\hline & yes & 0 & $0.00 \%$ & 27 & $61.40 \%$ & \\
\hline \multirow{2}{*}{ lip motions } & no & 44 & $100.00 \%$ & 41 & $93.20 \%$ & \multirow{2}{*}{0.121} \\
\hline & yes & 0 & $0.00 \%$ & 3 & $6.80 \%$ & \\
\hline \multirow{2}{*}{ tongue deviation } & no & 44 & $100.00 \%$ & 32 & $72.70 \%$ & \multirow{2}{*}{$<0.001 *$} \\
\hline & yes & 0 & $0.00 \%$ & 12 & $27.30 \%$ & \\
\hline \multirow{2}{*}{ cupping of the tongue } & no & 44 & $100.00 \%$ & 19 & $43.20 \%$ & \multirow{2}{*}{$<0.001^{*}$} \\
\hline & yes & 0 & $0.00 \%$ & 25 & $56.80 \%$ & \\
\hline \multirow{2}{*}{ mandibular vertical movements } & no & 44 & $100.00 \%$ & 14 & $31.80 \%$ & \multirow{2}{*}{$<0.001^{*}$} \\
\hline & yes & 0 & $0.00 \%$ & 30 & $68.20 \%$ & \\
\hline \multirow{2}{*}{ tongue blade deformation } & no & 44 & $100.00 \%$ & 39 & $88.60 \%$ & \multirow{2}{*}{$0.028^{*}$} \\
\hline & yes & 0 & $0.00 \%$ & 5 & $11.40 \%$ & \\
\hline \multirow{2}{*}{ variation of the articulation point } & no & 44 & $100.00 \%$ & 17 & $38.60 \%$ & \multirow{2}{*}{$<0.001^{*}$} \\
\hline & yes & 0 & $0.00 \%$ & 27 & $61.40 \%$ & \\
\hline \multirow{2}{*}{ variation of the manner of articulation } & no & 44 & $100.00 \%$ & 42 & $95.50 \%$ & \multirow{2}{*}{0.247} \\
\hline & yes & 0 & $0.00 \%$ & 2 & $4.50 \%$ & \\
\hline
\end{tabular}

Fisher's exact test. * statistical significance $=p<0.05$ 


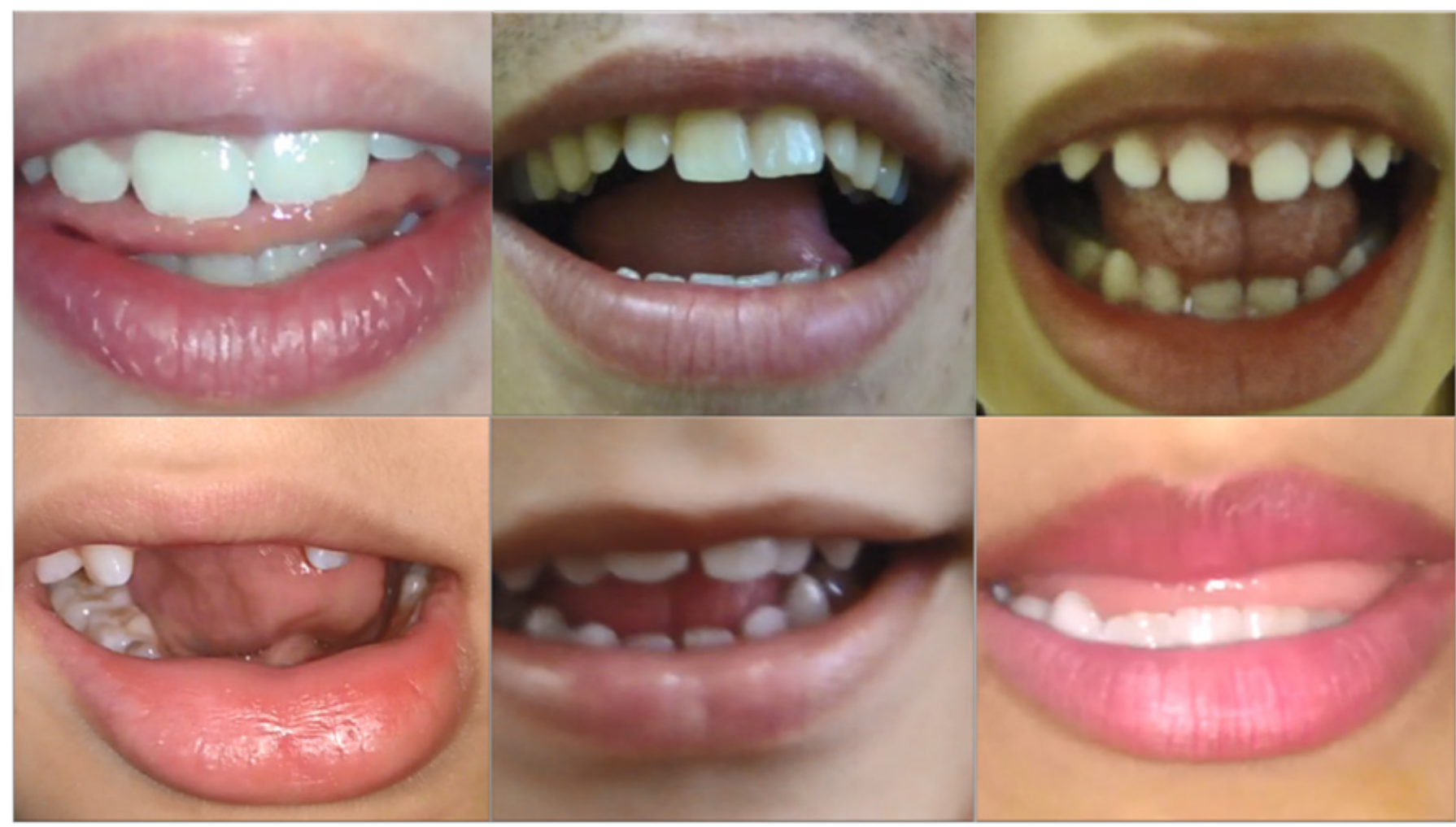

Figure 1. Compensatory tongue strategies when producing the alveolar flap sound/r/

\section{DISCUSSION}

In this study we characterized the compensatory strategies of 44 subjects with ankyloglossia when producing the alveolar flap / $/$ / of the Brazilian Portuguese. The literature reports that the acquisition of this sound is later, around 5 years of age ${ }^{15,24}$. For the adequate production of the alveolar flap $/ r /$, rapid, synchronous, and accurate tongue movements are required ${ }^{16}$. Although having restriction of tongue movements, the omission of the alveolar flap / $/$ / was not found in the subjects with ankyloglossia. However, all subjects produced the sound using one or more compensatory strategies, as reduced mouth opening, mandible deviation, elevation of the lateral sides of the tongue, tongue deviation, cupping of the tongue, mandibular vertical movements, tongue blade deformation, and variation of the articulation point when producing the alveolar flap. There was a statistically significant difference $(p=0.001)$ when comparing both the subjects with and without ankyloglossia.

The participation of the lips during the production of alveolar flap as well as the variation of the articulatory mode were not present in subjects without ankyloglossia ; however, a small number of subjects with ankyloglossia performed those compensations, demonstrating that these subjects can use a variety of strategies, which are not expected for the production of this sound.

These findings demonstrate that even with movement restrictions, the tongue is able to perform the alveolar flap using unusual compensatory strategies. The intrinsic muscles of the tongue, responsible for the precise speech movements, function as muscular hydrostats, altering the shape of the tongue so it can perform a greater variety of movements ${ }^{25,26}$.

Two studies assessed the speech production of subjects with ankyloglossia and concluded that the most frequent features were distortion, locked articulation, and low tongue posture ${ }^{22,27}$. Both studies assessed the general characteristics of the speech production; however, they did not investigate how the altered sounds were produced.

The compensatory strategies described above also varied from subject to subject, and there was no single compensation pattern that could characterize the production of the alveolar flap in cases of ankyloglossia. Nevertheless, all alveolar flap productions differed from the way that subjects without ankyloglossia produced this sound. A literature review demonstrated that in the presence of ankyloglossia the phone that is most frequently altered is the alveolar flap $/ r /$, and that 
subjects with ankyloglossia compensate in order to minimize tongue movement restrictions ${ }^{28}$.

It is important to highlight that compensatory strategies were observed even in speech productions considered auditively normal. These findings demonstrate the importance of visual analysis of lip, tongue, and mandible movements during speech production in subjects with ankyloglossia, as reported in the literature ${ }^{18}$ and not only the auditory-perceptual analysis.

One limitation of this study is the lack of examinations such as electropalatography and ultrasound, which allow both real-time visualization of the tongue movements and the observation of the articulatory adjustments involved in the production of the alveolar flap, which are not auditively perceived. One suggestion for future studies is to include those examinations for further speech production analyses.

\section{CONCLUSION}

The results demonstrated that subjects presented with ankyloglossia use several lip, tongue, and mandible compensatory strategies to produce the Brazilian Portuguese consonantal alveolar flap sound $\mid r /$.

\section{REFERENCES}

1. Schoenwolf GC, Bleyl SB, Brauer PR, Francis-West $\mathrm{PH}$. Larsen's human embryology. vol 5th ed. Churchill Livingstone; 2015.

2. Ganesan K, Girgis S, Mitchell S. Lingual frenotomy in neonates: past, present, and future. $\mathrm{Br} \mathrm{J}$ Oral Maxillofac Surg. 2019: in Press.

3. Pakanati SSR, Anchery VA, Moidu F. Familial ankyloglossia [tongue - tie] - A rare case report. J. Evolution Med Dent Sci. 2014;3(2):303-5.

4. Soman C, Lingappa A. Robinow Syndrome: a rare case report and review of literature. Int $\mathrm{J}$ Clin Pediatr Dent. 2015;8(2):149-52.

5. Ohlstein JF, Padilla PL, Garza RK, Masel BD, Abouleish A, Pine HS et al. Ankyloglossum Superius Syndrome compromising a neonatal airway: considerations in congenital oral airway obstructions. Int $\mathrm{J}$ Pediatr Otorhinolaryngol. 2019;117:167-70.

6. Baş S, Baş V, Irmak F, Karşıdağ SH. Congenital lateral cleft palate with unilateral craniofacial microsomia and lateral ankyloglossia. BMJ Case Rep. 2019;12(1)pii: e226104.
7. Martinelli RLC, Marchesan IQ, Berretin-Felix G. Longitudinal study of the anatomical characteristics of the lingual frenulum and comparison to literature. Rev. CEFAC. 2014;16(4):1202-7.

8. Martinelli RLC, Marchesan IQ, Gusmão RJ, Rodrigues AC, Berretin-Felix G. Histological characteristics of altered human lingual frenulum. Int. J. Pediatr. Child Health. 2014;2:5-9.

9. Mills N, Pransky SM, Geddes DT, Mirjalili SA. What is a tongue tie? Defining the anatomy of the in-situ lingual frenulum. Clin Anat. 2019 Jan 30. doi: 10.1002/ca.23343. [Epub ahead of print].

10. Geddes D, Langton D, Gollow I, Jacobs L, Hartmann $P$, Simmer K. Frenulotomy for breastfeeding infants with ankyloglossia: effect on milk removal and sucking mechanism as imaged by ultrasound. Pediatrics. 2008;122(1):e188-94.

11. Stavness I, Lloyd JE, Fels S. Automatic prediction of tongue muscle activations using a finite element model. J Biomech. 2012;45(16):2841-8.

12. Elad D, Kozlovsky P, Blum O, Laine AF, Po MJ, Botzer $E$ et al. Biomechanics of milk extraction during breast-feeding. Proc Natl Acad Sci USA. 2014;111(14):5230-5.

13. Xu K. 3D tongue motion visualization based on the B-mode ultrasound tongue images [tesis]. Paris: Computer Aided Engineering, Université Pierre et Marie Curie; 2016.

14. Martinelli RLC, Fornaro EF, Oliveira CJM, Ferreira LMDB, Rehder MIBC. Correlações entre alterações de fala, respiração oral e oclusão. Rev. CEFAC. 2011;13(1):17-26.

15. Pagan LO, Wertzner HF. Análise acústica das consoantes líquidas do Português Brasileiro em crianças com e sem transtorno fonológico. Rev Soc Bras Fonoaudiol. 2007;12(2):106-13.

16. Fonseca RP, Dornelles S, Ramos AP. Relação entre a produção do $r$-fraco e as praxias linguais na infância. Pró-Fono R. Atual. Cientifc. 2003;15(3):229-40.

17. Gonçalves CS, Ferreira MC. Estudo da relação entre presença de frênulo lingual curto e/ou anteriorização e a dorsalização do fone $/ r /$ na articulação da fala. Rev. CEFAC. 2006;8(1):56-60.

18. Ostapiuk B. Asymmetry in sound production in persons with ankyloglossia. Logopedia. 2010;39/40:113-37.

19. Dollberg S, Manor Y, Makai E, Botzer E. Evaluation of speech intelligibility in children with tongue-tie. Acta Paediatr. 2011;100(9):e125-7. 
20. Messner AH, Lalakea ML. The effect of ankyloglossia on speech in children. Otolaryngol Head Neck Surg. 2002;127(6):539-45.

21. Marchesan IQ, Teixeira AN, Cattoni DM. Correlações entre diferentes frênulos linguais e alterações na fala. Disturb. Comun. 2010;22(3):195-200.

22. Braga LAS, Silva J, Pantuzzo CL, Motta AR. Prevalência de alteração no frênulo lingual e suas implicações na fala de escolares. Rev. CEFAC. 2009;11(Supl3):378-90.

23. Marchesan IQ. Protocolo de avaliação do frênulo da língua. Rev. CEFAC. 2010;12(6):977-89.

24. Oliveira MM, Wertzner $H$. Estudo do distúrbio fonológico em crianças. R. Soc. Bras. Fonoaudiol. 2000;7(2):68-75.

25. Sanders I, Mu L, Amirali A, Su H, Sobotka $S$. The human tongue slows down to speak: muscle fibers of the human tongue. Anat Rec. 2013;296(10):1615-27.

26. Sanders I, Mu L. A three-dimensional atlas of human tongue muscles. Anat Rec. 2013;296(7):1102-14.

27. Suzart DD, Carvalho ARR. Speech disorders related to alterations of the lingual frenulum in schoolchildren. Rev. CEFAC. 2016;18(6):1332-9.

28. Marchesan IQ,Teixeira AN, Cattoni DM. Correlações entre diferentes frênulos linguais e alterações na fala. Distúrb. Comum. 2010;22(3):195-200. 